\title{
EFEKTIFITAS PEMBERIAN EKSTRAK JAHE TERHADAP INTENSITAS DISMENORE PADA MAHASISWI AKADEMI KEBIDANAN SAKINAH PASURUAN
}

\author{
Kurnia Dini Rahayu'), Lailatul Nujulah' ${ }^{2)}$ \\ Akademi Kebidanan Sakinah Pasuruan \\ Email: poncohadiwibowo@gmail.com
}

\begin{abstract}
ABSTRAK
Dismenore merupakan nyeri haid yang dapat mengakibatkan penurunan kualitas hidup. Dismenore pada remaja putri jika tidak segera diatasi akan berakibat mengganggu kegiatan sehari hari seperti absen dari sekolah sehingga terganggunya proses belajar. Kandungan oleoresin dalam jahe merah merupakan anti inflamasi dan analgetik yang dapat mengurangi intensitas dismenore dengan cara menghambat prostaglandin.

Penelitian ini adalah penelitian quasy eksperimental dengan desain penelitian one-group pretest-postest. Pengumpulan data dilakukan dengan lembar penilaian skala nyeri sebelum dan sesudah diberikan ekstrak jahe merah. Sampel penelitian ini adalah mahasiswi Akademi Kebidanan Sakinah Pasuruan yang mengalami dismenore yaitu sebanyak 33 mahasisiwi. Dismenore diukur menggunakan skala numerik dengan skala 0-10. Data penelitian diuji menggunakan uji statistik $t$ test

Hasil penelitian menunjukkan bahwa intensitas nyeri sebelum intervensi hampir seluruh responden dengan nyeri berat dan sesudah intervensi hampir seluruhnya dengan nyeri sedang. Hasil analisa didapatkan ada perbedaan antara intensitas nyeri sebelum intervensi dengan sesudah intervensi ( $p$ value 0,000 ).

Pemberian ekstrak jahe merah $250 \mathrm{mg}$ diminum selama tiga hari sebelum haid dan hari pertama haid, efektif dapat menurunkan dismenore. Dengan demikian ekstrak jahe merah dapat menjadi salah satu alternatif pengobatan non farmakologi dalam penanganan nyeri dismenore.
\end{abstract}

Kata Kunci : Dismenore, Ekstrak jahe, Remaja Putri

\section{PENDAHULUAN}

Salah satu proses kematangan seorang perempuan adalah menstruasi atau haid. Menarche atau menstruasi awal biasanya terjadi antara usia 9-12 tahun, akan tetapi ada yang mengalami keterlambatan yaitu antara usia 13-15 tahun. Rata-rata lama menstruasi antara 3- 8 hari dengan rata-rata siklus menstruasi 28 hari (Anurogo, 2011).

Dismenore primer paling sering terjadi pada remaja putri (primary dysmenorrrhea). Sekitar 50\% wanita usia reproduksi mengalami dismenore (Tracey,2007) dan 60$80 \%$ pada remaja dan $67 \%$ pada umur dewasa yang mengakibatkan aktifitas belajar di sekolah terganggu (Woo and Eneaney, 2013). Dismenore primer adalah suatu gejala atau rasa sakit saat menstruasi yang tidak disertai dengan kelainan patologi pada organ reproduksi wanita (Sogi, 2011).

Ada bermacam teknik digunakan baik secara farmasi maupun herbal untuk mengurangi bahkan menghilangkan dismenore. Obat antinyeri merupakan pilihan utama yang digunakan oleh perempuan untuk mengurangi dismenore. Obat-obatan tersebut mempunyai dampak yang merugikan (Harel, 
2006). Metode lain yang dipakai secara tradisional dengan obat-obat tradisional yang bersumber dari tanaman. Asam jawa, kunir, jahe, kayu manis, dan cengkeh merupakan beberapa tanaman yang dapat menurunkan rasa sakit (Anurogo, 2011).

Jahe merupakan salah satu terapi herbal yang dapat digunakan, mudah didapat, murah dan terjangkau. Jahe efektif menurunkan rasa nyeri sama dengan obat analgetik asam mefenamat dan ibuprofen (Anurogo, 2011). Jahe menjadi pilihan karena mengandung banyak oleoresin. Oleoresin adalah komponen bioaktif terdiri dari gingerol dan shogaol yang bekerja sebagai antiinflamasi sehingga prostaglandin dapat terblokir (Ozgoli, et.all, 2009).

\section{METODE PENELITIAN}

Metode penelitian adalah penelitian quasy eksperimen dengan desain penelitian one group pretest-posttest dimana dalam pelaksanaannya diberikan perlakuan dengan memberikan kapsul yang berisi ekstrak jahe merah. Ekstrak jahe merah diberikan saat hari ke tiga sebelum menstruasi sampai dengan hari pertama menstruasi, dengan takaran satu kapsul berisi $250 \mathrm{mg}$ ekstrak jahe merah, diminum sehari tiga kali.

Intensitas dismenore diukur sebelum perlakuan dengan cara, pada haid bulan pertama dan kedua mahasiswa diminta untuk mengisi lembar penilaian nyeri. Untuk mengukur intensitas nyeri digunakan skala sederhana pengukuran nyeri yaitu skala numerik. Skala 1-3 kategori nyeri ringan, skala
4-6 nyeri sedang, skala 7-9 nyeri berat, skala 10 nyeri sangat berat Penelitian ini dilakukan di Akademi Kebidanan Sakinah Pasuruan.

Sampel dalam penelitian ini adalah semua mahasiswi Akademi Kebidanan Sakinah dengan kriteria penelitian yang ditentukan peneliti yaitu: 1) mahasiswi yang mengalami dismenorea hari ke 1-3 menstruasi, 2) mahasiswa yang bersedia menjadi responden. Teknik pengambilan sampel dalam penelitian ini adalah purposive sampling dengan besar sampel 33 mahasiswi.

Hasil penelitian ditabulasi untuk selanjutnya dilakukan analisis. Dalam menganalisis data secara bivariat, pengujian data dilakukan dengan uji statisik uji t-paired yang digunakan untuk membandingkan dismenore sebelum dan sesudah perlakuan. Tingkat kemaknaan $\alpha=0,05$. Untuk memudahkan perhitungan dan mengurangi tingkat kesalahan dalam analisa data, digunakan alat bantu software SPSS 16 for windows.

\section{HASIL PENELITIAN}

Hasil analisis statistik deskriptif berdasarkan umur, lama menstruasi, riwayat dismenore dan nyeri sebelum diberikan intervensi dapat dilihat pada tabel 1.

Tabel 1 Hasil Analisis Statsitik Deskriptif terhadap Umur, Lama Menstruasi, Nyeri haid

\begin{tabular}{lccc}
\hline Variabel & Minimum & Maximum & Mean \\
\hline Umur & 18 & 22 & 20.42 \\
Menarche & 9 & 16 & 13,33 \\
Lama haid & 3 & 10 & 7,42 \\
Lama nyeri & 1 & 5 & 2,67 \\
Nyeri haid & 3 & 10 & 5,82 \\
\hline
\end{tabular}


Pada tabel 1 dapat dilihat bahwa umur rata-rata responden yang dismenore adalah 20 tahun, kemudian rata-rata lama menstruasi responden dismenore adalah 7 hari, sedangkan usia pertama kali haid rata-rata usia 13 tahun dan rata-rata responden mengalami nyeri sedang.

Tabel 2 Distribusi Frekuensi Penatalaksanaan Dismenore

\begin{tabular}{|c|c|c|}
\hline Jenis Penanganan & f & $\%$ \\
\hline Minum obat antinyeri & 5 & 15,15 \\
\hline Minum jamu & 7 & 21,2 \\
\hline Istirahat & 5 & 15,15 \\
\hline Kompres air hangat & 3 & 9,09 \\
\hline Minum air putih & 2 & 6,06 \\
\hline $\begin{array}{l}\text { Lain lain } \\
\text { (beraktifitas,minum } \\
\text { air hangat, olahraga, } \\
\text { minum susu) }\end{array}$ & 11 & 33,3 \\
\hline
\end{tabular}

Tabel 2 memperlihatkan bahwa hampir sebagian responden yaitu 33,3\% mengurangi dismenore dengan beraktifitas, minum air hangat, minum susu, sedangkan sebagian kecil responden yaitu 6,06\% responden mengurangi dismenore dengan minum air putih.

Tabel 3 Tabulasi silang nyeri sesudah dan sebelum pemberian ekstrak jahe merah

\begin{tabular}{lcccc}
$\begin{array}{c}\text { Dismenore } \\
\text { setelah diberi } \\
\text { ekstrak jahe }\end{array}$ & $\begin{array}{c}\text { Nyeri } \\
\text { Ringan }\end{array}$ & $\begin{array}{c}\text { Nyeri } \\
\text { Sedang }\end{array}$ & $\begin{array}{c}\text { Nyeri } \\
\text { Berat }\end{array}$ & Total \\
$\begin{array}{l}\text { Debelum diberi } \\
\text { ekstrak jahe }\end{array}$ & & & & \\
\hline Nyeri sedang & 3 & 0 & 0 & 3 \\
\hline Nyeri berat & 0 & 17 & 0 & 17 \\
\hline Sangat nyeri & 0 & 7 & 3 & 10 \\
\hline 6 & 0 & 2 & 1 & 3 \\
\hline Total & 3 & 26 & 4 & 33 \\
\hline
\end{tabular}

Dari tabel 3 dapat dijelaskan bahwa sebagian besar tingkat nyeri responden adalah berat, sedangkan setelah diberikan ekstrak jahe merah responden mengalami nyeri sedang.

Tabel 4 Perbedaan Intensitas Nyeri Sebelum dan Sesudah Intervensi

\begin{tabular}{|c|c|c|c|c|c|}
\hline $\begin{array}{l}\text { Intensitas } \\
\text { Nyeri }\end{array}$ & $\mathbf{N}$ & Mean \pm SD & $\begin{array}{l}\text { Koefi } \\
\text { sien } \\
\text { Korel } \\
\text { asi (r) }\end{array}$ & $\begin{array}{l}\text { Perbed } \\
\text { aan } \\
\text { Rerata } \\
\text { (IK } \\
\text { 95\%) }\end{array}$ & $\begin{array}{l}P \\
\text { value }\end{array}$ \\
\hline Sebelum & 33 & $\begin{array}{l}3.39 \pm 0.78 \\
8\end{array}$ & \multirow[t]{2}{*}{.646} & \multirow{2}{*}{$\begin{array}{l}1.150- \\
1.577\end{array}$} & \multirow[t]{2}{*}{.000} \\
\hline Sesudah & 33 & $\begin{array}{l}2.03 \pm .0 .4 \\
67\end{array}$ & & & \\
\hline
\end{tabular}

diketahui rata-rata intensitas nyeri sebelum diberikan intervensi ekstrak jahe yaitu sebesar 3,39 dan sesudah diberikan ekstrak jahe adalah sebesar 2,03. Penurunan nilai ratarata intensitas nyeri pada responden sebelum dan sesudah sebesar 1,364 , sehingga dapat dinyatakan nyeri sebelum dan sesudah diberikan ekstrak jahe merah mengalami penurunan.

Hasil uji statistik menunjukkan nilai koefisien korelasi $(r)$ yang menunjukkan besarnya hubungan antara sebelum dan sesudah intervensi sebesar 0,646 menunjukkan bahwa ada korelasi yang kuat dan berpola positif antara sebelum dan sesudah pemberian ekstrak jahe. Hasil analisis statistik menunujkkan nilai $p$ value sebesar $0,000(p<0,05)$ sehingga disimpulkan ada perbedaan rata-rata intensitas nyeri yang signifikan antara sebelum dan sesudah diberikan intervensi ekstrak jahe. 


\section{PEMBAHASAN}

Nyeri merupakan reaksi penting bagi tubuh terhadap provokasi saraf saraf sensorik nyeri yang dapat menimbulkan reaksi ketidakyamanan (Guyton, 2007). Nyeri menstruasi atau dismenore terjadi akibat keluarnya hormon prostaglandin dari sel-sel dinding endometrium yang mengalami deskuamasi karena penurunan hormon estrogen progesteron sehingga menyebabkan iskemia jaringan (Prawirohardjo, 2010). Ovarium merupakan organ yang penting dalam produksi prostaglandin di dalam uterus. Kadar prostaglandin dalam jumlah yang besar akibat dari tingginya kadar estrogen pada saat fase lutheal (Lumsden, 2005).

Dismenore juga menimbulkan dampak pada aktivitas/kegiatan wanita khususnya remaja. Dismenore membuat remaja absensi dari sekolah atau kuliah sehingga menyebabkan kualitas hidup wanita menurun (Prawirohardjo, 2010). Hampir seluruh wanita menggunakan obat-obatan antinyeri untuk mengatasi dismenore (Dawood, 2006). Penanganan awal untuk dismenore tanpa abnormalitas organ reproduksi (dismenore primer) adalah dengan pemberian obat analgesik dan sekitar $80 \%$ penderita mengalami penurunan rasa nyeri setelah meminum obat antiprostaglandin yaitu ibuprofen, asam mefenamat, dan aspirin, akan tetapi obat-obatan tersebut menyebabkan efek samping gangguan pada saluaran pencernaan seperti mual, muntah, dan rasa penuh di lambung (Harel, 2006).
Jahe (Zingiber officinale) adalah salah satu tanaman yang dipercaya dapat menurunkan rasa nyeri menstruasi. Jahe merah bersifat menghangatkan tubuh, antirematik, antiinflamasi dan antinyeri. Senyawa shogaol dan gingerol merupakan senyawa yang terdapat pada jahe yang dapat mengurangi rasa nyeri. Jahe sebagai antinflamasi mempunyai cara kerja dengan menghambat kerja enzim siklus cyklooksigenase (COX) sehingga dapat menghambat pelepasan enzim tersebut menuju prostaglandin penyebab terjadinya inflamasi. Hal ini akan menyebabkan terjadinya prostaglandin dan leukotrien yang merupakan mediator radang menurun sehingga jahe direkomendasikan untuk perempuan khususnya remaja putri yang menderita dismenore (Ozgoli, et.all, 2009).

Hasil penelitian menyatakan bahwa terdapat perbedaan antara penurunan intensitas nyeri sebelum dan sesudah diberikan intervensi ekstrak jahe. Hal ini ini diperkuat dengan penelitian lain yang menyatakan bahwa jahe memiliki efektifitas menurukan rasa nyeri sama dengan asam mefenamat dan ibuprofen (Black, et.all, 2010). Berdasarkan penelitian yang sebelumnya bahwa jahe dapat digunakan selama 3 bulan sampai dengan 2,5 tahun tanpa efek samping (Rahnama, et.all,2012).

Penurunan intesitas dismenore yang dialami responden dikarenakan adanya impuls rasa hangat yang merupakan efek dari ekstrak jahe yang mengenai bagian yang terasa nyeri yaitu perut bagian bawah. Rasa 
hangat dari jahe direspon oleh ujung syaraf yang berada di dalam kulit dan sensitif terhadap suhu. Stimulasi ini mengirimkan impuls dari saraf tepi ke otak besar sehingga timbul kesadaran terhadap suhu lokal dan memicu reaksi tubuh untuk mempertahankan suhu normal tubuh (Potter and Perry, 2005).

\section{KESIMPULAN}

Rata-rata intensitas dismenore sebelum dilakukan intervensi adalah nyeri sedang dan rata rata nyeri sesudah dilakukan intervensi adalah nyeri ringan .Berdasarkan uji statsitik dinyatakan bahwa terdapat perbedaan anatara penurunan intensitas nyeri sebelum dan sesudah diberikan intervensi ekstrak jahe merah ( $p$ value 0,000 ). Sehingga ekstrak jahe dapat dijadikan salah satu alternatif pilihan pengobatan non farmakologi (herbal) untuk mengurangi nyeri dismenore.

\section{SARAN}

Sebagai bahan pertimbangan atau masukkan dalam bidang kesehatan terutama promotif dan preventif sehingga derajat kesehatan dan kualitas hidup masyarakat meningkat terutama mahasiswi Akademi Kebidanan Sakinah Pasuruan. Hasil penelitian dapat dimanfaatkan oleh mahasiswi Akbid Sakinah Pasuruan untuk mengatasi dismenore secara non farmakologis.

\section{DAFTAR PUSTAKA}

Anurogo, W. 2011.Cara Jitu Mengatasi Nyeri Haid.Yogyakarta:C.V Andi Offset
Black C.D, Herring M.P, Hurley D.J, O'Connor P.J.2010.Ginger (Zinger Officinale) Reduces Muscle Pain Caused By Eccetric Exercise.The Journal of Pain

Dawood.M.Y.2006. Primary Dysmenorrhoea: Advances In Pathogenesis and Management..Vol 108.Clinical Expert Series: American College of Obstretrician and Gynecologis

Giti Ozgoli, Marjan Goli, Fabiroz Moattar.2009. Comparison with Primary Dymesnorrhoea of Ginger, Mefenamic Acid and Ibuprofen On Pain In women With Primary Dysmenorrhoea.Journal Of Alternatif and Complementary Medicine Vol 15

Guyton A.C and Hall J.E.2007.Buku Ajar Fisiologi Kedokteran, 11 th ed.Jakarta

Harel.Z.2006.Dysmenorrhoae In Adolescent and Young Adults: Etiology and Management. North American Society for Pediatric and Adolescent Gynecology: Published Elsiever

Kelly Tracey.2007.5 Rahasia Alami Meringankan Sindrom Pramenstruasi.Jakarta: Erlangga Lumsden.M.A.2005.Dysmenorrhoea.Women' $s$ Heath Medicine

Potter, P.A and Perry, A.G. 2005. Buku Ajar Fundamental Keperawatan Konsep dan Praktik.Edisi 4.EGC: Jakarta.

Prawirohardjo.S.2007. IImu Kebidanan.YBPSP: Jakarta.

Rahnama $\mathrm{P}$, Montazeri A, Huseini H., Kianbakht S, M.Naseri. 2012. Effect of Zingeiber Officinale $R$ Rhizomes (Ginger) On Pain Relie In Primary Dymenorrhoea: $\quad A$ Placebo Randomzied Trial.Department of Midwifery, Herbal Research Center, Shahed University: Tehran, Iran

Sogi DH, Harliyanti. Faktor-faktor yang berhubungan dengan siklus menstruasi pada mahasiswa Akbid Sari Mulia Banjarmasin.2011. 
Banjarmasin: Media Sains. 2013;

5:116-20

Woo.P, Mc.Eneaney. M. J. 2013. New

Strategies To Treat Primary

Dysmenorrhoae.The Clinical Advisor 